\title{
EL "NUEVO" JOVEN Y EL "VIEJO" RADIO: LA RELACIÓN DEL PÚBLICO JOVEN CON EL RADIO EN LA ACTUALIDAD
}

Rodrigo Lúcio-Cardoso: Universidade Luterana do Brasil en Canoas, Brasil rodrigolucio@hotmail.com

Cristianne Maria Famer-Rocha: Universidade Federal do Rio Grande do Sul en Porto Alegre, Brasil

cristianne.rocha@ ufrgs.br

\section{RESUMEN}

La relación del joven con los medios de comunicación se está modificando principalmente debido a la introducción a las nuevas tecnologías en la sociedad contemporánea. Con el objetivo de analizar la relación del público joven con el radio, se aplicó un cuestionario en 349 sujetos (jóvenes de 15 a 24 años, clase AB, residentes en Porto Alegre, RS), en el período de enero a mayo del 2010. Entre las principales conclusiones, destacamos que el radio se configura, en la actualidad, como un "vehículo de movimiento", oído principalmente en el carro o en el celular/mp3 player.

PALABRAS CLAVE: Radio - Joven - Medios de difusión - Nuevas tecnologías

\section{THE "NEW" YOUNGSTER AND THE "OLD" RADIO: THE RELATIONSHIP BETWEEN THE YOUNG AUDIENCE AND THE RADIO IN PRESENT TIMES}

\begin{abstract}
The relationship of the youngsters with the media is changing, mainly due to the introduction of new technologies in the contemporaneous society. In order to analyze the relationship of the young audience with the radio, a questionnaire was applied to

\footnotetext{
${ }_{1}^{1}$ Autor correspondiente

Rodrigo Lúcio-Cardoso: Universidade Luterana do Brasil (ULBRA). Canoas (Brasil).

Correo: rodrigolucio@hotmail.com
} 
349 subjects (15 to 24 year-old, AB social class youngsters who live in Porto Alegre, RS) between January and May of 2010. Among the main conclusions, we highlight that, in present times, the radio constitutes a "vehicle of movement," listened to mainly in the car or by the cell phone/ mp3 player.

KEY WORDS: Radio - Youngster - Media - New technologies

\section{O "NOVO" JOVEM E O “VELHO" RÁDIO: A RELAÇÃO DO PÚBLICO JOVEM COM O RÁDIO NA ATUALIDADE}

\section{RESUMO}

A relação do jovem com os meios de comunicação está se modificando principalmente devido à introdução das novas tecnologias na sociedade contemporânea. A fim de analisar a relação do público jovem com o rádio, foi aplicado um questionário em 349 sujeitos (jovens de 15 a 24 anos, classe AB, residentes em Porto Alegre, RS), no período de janeiro a maio de 2010. Dentre as principais conclusões, destacamos que o rádio se configura, na atualidade, como um "veículo de movimento", ouvido principalmente no carro ou no celular/mp3 player.

PALAVRAS CHAVE: Rádio - Jovem - Mídia - Novas tecnologias

\section{INTRODUCÇÃO}

\subsection{Sobre as intenções}

Em meio à revolução digital em que vivemos, o número de jovens com acesso à internet e às novas tecnologias cresce a cada dia. Ao mesmo tempo, com a popularização de aparelhos que reproduzem música digital (mp3 players, celulares, etc), a facilidade de acesso a qualquer música via download na internet, somado ao crescente número de web radios, colocam as emissoras de rádio convencional em uma complicada situação.

Essa realidade é proveniente da capacidade do jovem de se adaptar facilmente às novidades e, como se fosse o outro lado da mesma moeda, se cansar rapidamente do "velho", exigindo soluções diferentes a todo momento. Além do fato de termos, na atualidade, uma grande opção de mídias que dividem a atenção do público, tornando mais difícil a tarefa de conquistar e reter o mesmo.

Segundo a pesquisa Dossiê MTV Universo Jovem (MTV, 2008), 69\% dos jovens brasileiros costuma fazer download de música na internet e $73 \%$ ouvem música online. Em outra pesquisa, realizada pela revista Veja, Buchalla (2009) apresenta estimativas 
de que $92 \%$ dos jovens de classe alta do Brasil possuem celular e $61 \%$ usam o aparelho como forma de entretenimento, para jogar e/ou ouvir música. Tais dados reforçam a ideia de como o público jovem é dependente de música e de tecnologia. Agora, resta saber como o rádio se insere nessa nova realidade jovem. Ou melhor: como o "novo" jovem se relaciona com o "velho" rádio?

Para descrever e analisar como o público jovem, de 15 a 24 anos $^{2}$, classe AB, residente em Porto Alegre (RS), se relaciona com o meio rádio, foi realizada uma investigação exploratória, de abordagem mista (qualitativa e quantitativa). $\mathrm{O}$ instrumento de coleta de dados utilizado foi um questionário semi-estruturado, aplicado em diversos pontos da cidade de Porto Alegre, onde o público-alvo pode ser encontrado, tais como: cursinhos pré-vestibulares, escolas de idiomas e universidades.

Para a elaboração do questionário de pesquisa, foi utilizado o Critério de Classificação Econômica Brasil (CCEB), da Associação Brasileira de Empresas de Pesquisa (ABEP, 2010), onde a divisão de mercado definida é a de classes econômicas. O tamanho da amostra da pesquisa foi definido junto ao Setor de Estatística da Universidade Luterana do Brasil (ULBRA) e a mesma foi selecionada de forma aleatória simples, segundo Mattar (2001). Sendo assim, se chegou ao número de 349 questionários e um erro máximo estimado de 5,3\%.

\section{METODOLOGIA}

A nossa metodologia foi desenvolvida sobre a base de um questionário com o fim de analisar a relação do público jovem com o rádio, foi aplicado um questionário em 349 sujeitos (jovens de 15 a 24 anos, classe AB, residentes em Porto Alegre, RS), no período de janeiro a maio de 2010.

\section{ANÁLISE E DISCUÇÃO}

\subsection{O "Velho" Rádio}

O rádio é um meio de comunicação que, através de emissões de ondas eletromagnéticas, transmite mensagens sonoras. Segundo Rabaça e Barbosa (2001, p. 23):

O rádio pode ser definido como um "veículo de radiodifusão sonora que transmite programas de entretenimento, educação e informação. Música, notícias, discussões, informações de utilidade pública, programas humorísticos, novelas, narrações de acontecimentos esportivos e sociais, entrevistas e cursos são os gêneros básicos dos programas". Serviço prestado mediante concessão do Estado, que o considera de interesse nacional, e deve operar dentro de regras preestabelecidas em leis, regulamentos e normas.

\footnotetext{
${ }^{2}$ A segmentação etária foi realizada de acordo com a Organização das Nações Unidas para a Educação e Ciência (UNESCO), que define o público jovem como os indivíduos que possuem de 15 a 24 anos de idade.
} 
A criação do rádio se deu a partir do ano 1863, quando Samuel Finley Morse inventou o telégrafo eletromagnético (com fio) e o Código Morse, ainda hoje utilizados. Porém, é difícil atribuir a invenção do rádio a uma só pessoa e, sim, em uma sucessão de inventos e descobertas.

Segundo Ferrarreto (2000), a primeira rádio reconhecida no Brasil foi a Rádio Sociedade do Rio de Janeiro, em 1923. A partir dessa data, o rádio evolui no Brasil, onde passou por diversas fases: do rádio clube (onde a pessoa deveria ser sócia para ouvir a emissora), até as rádionovelas, programas de auditório, humorísticos e jornalísticos.

No entanto, com a chegada da televisão no Brasil, em 1951, chega ao fim a "era de ouro" do rádio. Com isso, a música passou a predominar nas FMs e se iniciou uma divisão do público, fenômeno esse que foi se consolidar nos anos 80 .

O futuro do rádio ainda é incerto e o surgimento e a popularização da internet afetam sua popularidade de forma direta e irreversível. Para Herschmann \& Kischinhevsky (2008, p. 104):

A reconfiguração das indústrias do rádio e da música causa impacto direto sobre o campo da cultura. Embora os podcasts ${ }^{3}$ e as web radios ${ }^{4}$ ainda constituam uma fração do mercado, representam a face mais visível de um processo de transformação da mídia sonora, redesenhando os circuitos de produção, veiculação e consumo da música popular massiva e da informação radiofónica

Além disso, Kischinhevsky (2009) afirma que o desenfreado avanço tecnológico acabou deixando o rádio analógico velho e, assim, longe do alvo dos consumidores. Em tempos de um acelerado processo de convergência de mídias, o rádio teria horizonte finito e necessariamente vinculado a outros suportes como o computador, por exemplo.

\subsection{Os "Novos" Jovens}

O termo "juventude" pode ser utilizado de diversas maneiras e pode apresentar diferentes sentidos em relação ao seu conceito que, por sua vez, está diretamente relacionado à palavra "jovem". A juventude, segundo consta no dicionário Michaelis (2010), é "o período da vida entre a infância e a idade adulta", ou seja, a adolescência. Segundo Costa (2010, p. 1):

\footnotetext{
3 Segundo Herschmann \& Kischinhevsky (2008), Podcast é um arquivo de áudio digital que é publicado na internet e tem distribuição livre. A palavra podcasting refere-se à forma de publicação desses arquivos, e é uma junção de IPod - marca do aparelho tocador de mp3 da empresa Apple de onde saíram os primeiros podcasts - e broadcasting (transmissão de rádio ou televisão).

${ }_{4}$ Web radio (também conhecido como rádio via internet ou rádio online) é um serviço de transmissão de áudio via internet com a tecnologia chamada streaming, que gera programação ao vivo ou gravada. Segundo Santini (2005), o leque de opções é grande. É possível ouvir na internet uma rádio convencional ou montar a sua própria rádio. E, além disso, web radios normalmente não possuem comerciais.
} 
O conceito de juventude pode variar de acordo com o interesse de quem o maneja, mas, normalmente, é entendida como uma faixa etária. Logo, "a maior parte das definições de juventude tem a preocupação mais voltada para a delimitação do fenômeno, do que para explicitação das dinâmicas que ocorrem nos limites estabelecidos". Bem ilustrativo dessa tendência é o enfoque das Nações Unidas, que define juventude pela idade do indivíduo. Segundo esse critério cronológico, jovem é a pessoa que esteja na faixa etária compreendida entre 15 e 24 anos.

Porém, nem todos os autores concordam com essa definição. Menandro, Trindade e Almeida (2003, p. 44) apontam que "a adolescência/juventude é objeto que foi construído culturalmente em nossas sociedades e transformado ao longo da história e dos contextos sociais".

Reforçando a tese de que seu significado está em constante transformação, Rocha e Pereira (2009, p. 15) afirmam:

Maiz significativo ainda é que a ideia de jovem e de juventude foi criada como um espaço liminar, uma espécie de lugar intermediário, que faz a transição entre uma maturidade adiada e uma infância espremida. Assim, é de sua natureza ser transição, algo como um limbo, uma passagem intermediária e, como tal, mediadora de diferenças entre estados diversos. Não por acaso, a adolescência é vista como um 'rito de passagem'.

Ainda de acordo com estes autores, o termo juventude começou a ser percebido somente a partir do século XIX e teve sua efetiva expansão durante a I Guerra Mundial - quando os jovens da frente de batalha se opuseram às velhas gerações de retaguarda. Antes disso, não havia esse "lugar intermediário" entre a infância e a vida adulta. Logo, a questão de transição e a ideia do "rito de passagem" para a vida adulta não existiam.

Para Savage (2009), o termo adolescência apareceu pela primeira vez em 1898, nos estudos do psicólogo G. Stanley Hall. Foi também Hall, em sua obra chamada Adolescence, quem primeiro definiu essa fase da vida com maior nitidez: de 14 a 24 anos. Ainda segundo Savage (2009), foi somente em 1944 que o termo teenager (adolescente, em português) ganhou força e espaço como denominador dessa faixa etária, alterando o conceito de juventude.

Sendo assim, a palavra juventude não pôde mais ser unicamente ligada à adolescência, visto que hoje o termo também é usado como um estado de espírito. Seria a chamada "visão romântica" do termo que, para Dayrell e Gomes (2010), parece associada a um tempo de liberdade e experimentações em diversas áreas, e não a uma faixa etária definida. Reforçando esse argumento, Rocha e Pereira (2009) descrevem que o conceito de juventude pode ainda ser considerado como parte de um fenômeno social, produto do imaginário coletivo, que influencia o comportamento dos indivíduos de todas as idades e como eles consomem produtos e ideias. 


\subsection{Os "Novos" Jovens nas redes}

Em 1951, Jerome David Salinger lançou sua obra mais conhecida: O Apanhador no campo de centeio. Nesse livro, o autor nos apresenta o jovem personagem Holden Caulfied, o questionador e rebelde adolescente que acha tudo uma droga e acabou por representar uma geração. Esse adolescente não existe mais. Pelo menos não dessa maneira. Para Buchalla (2009), os adolescentes de hoje ainda carregam um pouco da essência de Caulfield, mas, em geral, mudaram muito: ganharam liberdade, mas perderam o idealismo e o encantamento.

No entanto, na sociedade atual, ainda que os jovens contemporâneos não possuam aquele "espírito de mudança" ou aquela vontade de mudar o mundo que tinham no passado, a representação social que temos do jovem é marcada por um ideal de mudança. Mudança no sentido de estar constantemente em busca de algo novo, diferente. Mudança que se dá, principalmente, na maneira como os jovens se relacionam com o mundo em que estão inseridos.

Foi buscando conhecer esse público (ativo e sempre atualizado) e sua relação com o meio rádio (antigo e muito presente ainda hoje em nossas vidas), que foi realizada esta investigação junto a 349 jovens, residentes na cidade de Porto Alegre e pertencentes às classes A e B. Sendo mais específico, foram 21 jovens da classe A1, 109 da classe A2, 145 da classe B1 e 74 que fazem parte da classe B2. Desses jovens, 41,3\% são do sexo masculino e 58,7\% do sexo feminino. Todos tem idade entre 15 e 24 anos. Dos jovens entrevistados, $48,7 \%$ está cursando o ensino superior, $16,3 \%$ o ensino médio, $16 \%$ cursinho pré-vestibular, $16 \%$ não estuda no momento (o que não quer dizer que não esteja formado), e apenas 2,9\% ainda cursa o ensino básico.

Esses jovens, chamados por Buchalla (2009) de "frutos da revolução tecnológica e da globalização" (p. 86), podem ser classificados como um grupo bastante homogêneo e que possui como principal característica o consumo, tanto de bens materiais, quanto de ideias. Para Rocha e Pereira (2009), culturalmente, o consumo pode ser um sistema de significação, onde somos classificados pelos bens que possuímos. Sendo assim, podemos afirmar que o jovem, na atualidade, é um ser tecnológico conectado à banda larga. Já que, segundo dados da pesquisa realizada, 98,3\% dos entrevistados afirmaram ter acesso à internet de alta velocidade em casa, 94,1\% possuem computador desktop (de mesa) e 72,8\% tem acesso a notebooks e podem levar toda essa velocidade de informação na mochila para onde quiser.

Logo, a palavra do momento parece ser "mobilidade". Mobilidade esta que também está presente nos IPods, mp3 players e similares (os chamados gadgets) que 90,5\% dos entrevistados possuem. Assim, os gadgets possuem grande representatividade na vida social do joven e "no sistema de consumo adolescente, os gadgets, por suas características de comunicabilidade e, com ela, de gregarismo, desempenham papel fundamental. A tecnologia se transforma em bens de consumo, simbolizando identidades, estilos de vida, posições em uma hierarquia, transferindo e repondo distinção, prestígio, encanto, classificando, enfim, os semelhantes e os diferentes, as 
pessoas e as coisas" (Rocha \& Pereira, 2009, p. 95).

Assim, esses gadgets ganharam status social e fizeram com que o jovem acabasse se tornando o grande consumidor de tecnologia. Mas, não de qualquer tecnologia e, sim, da popularmente chamada "tecnologia de ponta". E a facilidade de operar qualquer advento tecnológico, por mais complexo que ele seja, é o que coloca essa geração à frente das anteriores.

De acordo com Buchalla (2009), essas novas tecnologias se tornaram extensões do corpo do jovem. O fato de levar o IPod, computador e videogame para onde for, faz com que o adolescente viva sempre em rede. $\mathrm{O}$ fato de estar sempre conectado faz com que tenha interesse por mais assuntos, ainda que (talvez) de maneira superficial. Afinal, hoje, o jovem tem acesso a uma variada e ilimitada gama de informações.

Uma pesquisa realizada pela McKinsey \& Company (2010), no Reino Unido, mostra que jovens entre 18 e 24 anos têm consumido em média 61 minutos diários de notícias. Um aumento de $33 \%$ em relação aos 46 minutos consumidos em pesquisa semelhante realizada em 2006. Outro dado relevante dessa pesquisa é que as pessoas, nessa faixa etária, afirmaram sentir a necessidade de serem os primeiros a saber da última notícia do momento. Mas essa crescente exposição a notícias - e informações como um todo não significa qualidade. Para Buchalla (2009, p. 88):

O lado ruim é que raramente tentam aprofundar-se em algum tema. Mudam de opinião com rapidez e freqüência proporcionais ao liga-desliga do computador. Mais do que ocorria nas gerações de jovens anteriores, suas decisões costumam estar envoltas em interrogações, com se a vida fosse um eterno teste de múltipla- escolha.

Não são poucas as opções disponíveis ao jovem, na atualidade. A TV por assinatura, por exemplo, é uma delas. Segundo dados da pesquisa realizada junto aos jovens porto- alegrenses, a TV por assinatura está presente em $80,5 \%$ dos lares desses jovens. Isso significa ter à disposição uma variada e (super) segmentada programação, que vai de filmes e séries até esportes e notícias (passando pela música e muitos outros assuntos), 24 horas por dia, ao alcance do controle remoto. E ainda: mais da metade dos jovens pesquisados - 54,4\% - possuem videogames, $48,5 \%$ tem acesso a jornais (através de assinatura paga) e 31,5\% recebem revistas em suas casas.

Para quem vive conectado, nunca foi tão fácil ter acesso a qualquer tipo de notícia, imagem, música, vídeo ou pessoa. Uma pesquisa realizada com internautas brasileiros pela E-Life (2010) mostra que o público jovem costuma ficar mais de 41 horas por semana na web. E boa parte dessas horas, os jovens estão conectados em redes sociais.

Em uma das questões da pesquisa realizada, objeto deste artigo, onde o entrevistado deveria escolher até três opções sobre quais seriam as atividades que fazem com maior freqüência, a internet levou uma pequena vantagem sobre a música: acessar redes 
sociais (Orkut, Twitter, Facebook, etc) recebeu 68,8\% das preferências. Provavelmente a já citada "eterna busca por algo novo" esteja diretamente relacionada a esse percentual, visto que novas redes sociais estão sempre surgindo e estimulando os internautas a delas fazerem parte.

O hábito de ouvir música (no IPod, celular ou mp3 players e similares) ficou em segundo lugar, com $67,6 \%$ dos votos dos pesquisados. Em terceiro lugar, com $49 \%$, a atividade realizada com maior freqüência, segundo os pesquisados, foi aquela de assistir filmes (no cinema, no DVD ou na internet). Em quarto lugar ficou a opção de praticar esportes, $(23,2 \%)$ e, em quinto, ler livros (20,6\%). Já o hábito de ouvir rádio ficou em sexto lugar (20,1\%) na preferência dos jovens entrevistados. Enquanto isso, atividades consideradas "culturais" e feitas no "mundo real", como ir ao teatro ou visitar museus e exposições, amargaram os últimos lugares da pesquisa, com 2,9\% e $1,7 \%$, respectivamente.

Isso nada mais é do que a comprovação do quanto a vida online está se tornando mais importante do que a vida offline. A esse fenômeno, Lemos e Cunha (2003) chamam de cibercultura, ou seja, o processo de troca entre o indivíduo, a cultura e a tecnologia e o quanto essa constante troca interfere em todas as ações sociais, não somente dos jovens. Da namorada (ou ficante) até o vestibular. Dos amigos da escola até a sua família. Das festas (ou baladas) até as viagens. Da música até o rádio. Tudo, ao que parece, para o novo jovem, está sendo mediado pelas tecnologias virtuais.

\subsection{O “Velho" Rádio e o “Novo" Jovem}

Durante algum tempo, o rádio foi sinônimo quase que exclusivamente de música. Principalmente para as emissoras FM. Porém, tal realidade vem sendo alterada com o avanço tecnológico. Segundo Kischinhevsky (2009), o rádio deixou de ser alvo do fetiche de consumidores e teve sua imagem desvinculada da música. Ou melhor, a música teve sua imagem desvinculada do rádio. Afinal, hoje é possível ouvir música no computador, na TV, no mp3 player, no celular e, até, no rádio. Tal versatilidade está diretamente relacionada ao fato de a música transcender as barreiras do mundo real/virtual e ter uma elevada representatividade na sociedade. Para Santini (2005, p. 15):

A música é um produto social e simbólico de grande importância nas diferentes formações culturais, principalmente se considerarmos a sua capacidade de criar vínculos afetivos entre as pessoas. A música pode usar diferentes formas de linguagem e expressão, sendo produto cultural de características muito especiais: nenhum produto cultural tem mostrado tamanha capacidade de adaptação aos diferentes meios de comunicação.

Logo, a música está presente em vários lugares, em diferentes momentos e situações. Tal prova disso é que 50,1\% dos jovens entrevistados na pesquisa realizada gastam entre duas e quatro horas de seu dia ouvindo música. E 25,2\% ouvem mais de quatro 
horas diárias, enquanto $24,6 \%$ ouvem uma hora ou menos. O meio preferido para ouvir música é o computador conectado à internet, com 44,7\% da preferência dos entrevistados. A segunda opção mais votada (em relação ao meio preferido para ouvir música) foram os famosos gadgets (IPod, mp3 player, celular, etc) com 38,1\%. Logo, podemos concluir que, se o jovem está em casa, ouve música no computador e, quando sai, opta pela mobilidade dos celulares e afins. Como terceira opção, aparecer o "velho" rádio com 10,6\% e, como última oção, a TV e seus canais musicais, com apenas $6 \%$.

Porém, a questão acima abre uma perspectiva para o "velho" rádio, já que gadgets como celulares e mp3 players também permitem ouvir estações de rádio. Isso foi abordado em uma pergunta sobre o hábito de consumo desses aparelhos. Aqui temos uma interessante discrepância entre jovens do sexo feminino e do masculino. Enquanto $66 \%$ dos jovens homens costumam ouvir somente o seu próprio playlist, o percentual entre o sexo feminino é menor: $40 \%$. Dentre os jovens que optam por ouvir alternadamente o seu próprio playlist e estações de rádio, também temos dados bastante diferenciados em relação ao gênero: $21,5 \%$ dos homens marcaram esta resposta, contra $44,4 \%$ das mulheres. Assim, podemos afirmar que as mulheres ouvem mais rádio do que os homens.

Outro dado interessante é que cerca de 7,2\% dos jovens pesquisados não utilizam nem o playlist nem as estações de rádio para ouvir música. Ou seja, utilizam outros meios, tal como os celulares. Isso se deve principalmente ao lançamento de aparelhos cada vez mais sofisticados que, ao agregarem mais funções, mudaram a forma de se utilizar o celular.

Mas, nesse mar de tecnologia, onde o "velho" rádio aparece?

Para a pesquisa realizada, o hábito de ouvir estações de rádio não desapareceu do público jovem. Entre os entrevistados, $63,9 \%$ ouvem ao menos uma hora de rádio por dia. Seguidos de 20,6\% daqueles que ouvem entre uma e duas horas e $12,9 \%$ que ouvem entre duas e quatro horas. Apenas 2,3\% afirmam ouvir mais de quatro horas diárias de programação de rádio.

O fato de ouvirem, em média, menos de uma hora por dia, se explica quando analisamos onde eles mais ouvem: no carro (35,8\% de votos). E, ainda mais, se considerarmos que $16,9 \%$ ouvem no celular e $14,6 \%$ no mp3 player. Enquanto isso, o número de pessoas que ouve rádio em casa chega aos 20,9\% dos entrevistados. Tais percentuais indicam o quanto o rádio hoje está sendo utilizado pelas pessoas "em movimento".

Será que o meio rádio, tal como o conhecemos hoje, está chegando ao fim? Ou será que a mudança paradigmática - a qual Jenkins (2009) se refere abaixo - produzirá efeitos irreversíveis para a manutenção do rádio? Segundo o autor:

Os mercados midiáticos estão passando por mais uma mudança de paradigma. 
Acontece de tempos em tempos. Nos anos 1990, a retórica da revolução digital continha uma suposição implícita, e às vezes explícita, de que os novos meios de comunicação eliminariam os antigos, que a internet substituiria a radiodifusão e que tudo isso permitiria aos consumidores acessar mais facilmente o conteúdo que mais lhes interessasse" (Jenkins, 2009, p. 31-32).

Talvez a salvação do rádio esteja diretamente associada à sua capacidade de, rapidamente, informar e prestar serviços a diferentes públicos a respeito dos acontecimentos quotidianos, independente do lugar em que seus ouvintes se encontrem. Porém, com os gadgets em alta, principalmente entre o público jovem, as emissoras de rádio destinadas exclusivamente à transmissão musical talvez percam cada vez mais espaço para mídias mais modernas e mais rápidas.

Mesmo assim, isso não deixa de lado a importância da informação no meio rádio. Para os jovens pesquisados, a informação no rádio é vista como importante (45\%) ou muito importante $(18,9 \%)$. Somente $8,6 \%$ classificaram a mesma como pouco importante. Mas, em contraponto a isso, temos $20,1 \%$ que afirma ser indiferente ao assunto e 7,4\% que prefere ouvir somente música e não acha a informação no rádio um fator importante. A importância da veiculação de informações, pelo rádio, atestada pela maior parte dos entrevistados, talvez esteja diretamente relacionada à capacidade desse veículo de informar com rapidez. Ou seja, ao ligar o rádio e ouvir o locutor informar, por exemplo, sobre um acidente aéreo que acabou de acontecer, é muito provável que o ouvinte corra à internet para ter maiores detalhes sobre o ocorrido. Portanto, é possível afirmar que a "fome" por informação seja eterna, mas o meio pelo qual os ouvintes/leitores/telespectadores "matam" esta fome, na atualidade, difere daqueles tempos áureos em que outros meios, dentre eles o rádio, reinavam absolutos.

Além disso, a informação está cada vez mais segmentada. Hoje em dia, é possível achar um podcast sobre praticamente qualquer assunto na internet. De música até cinema, passando por games, finanças, automóveis, saúde, humor, etc. E ainda assuntos mais focados, como ensino de línguas, história brasileira, religião, etc. E, além disso, qualquer pessoa com um computador ligado à internet e um microfone pode fazer o seu podcast e publicá-lo online. Para se ter uma idéia, o site PodCastOne é atualmente um dos maiores portais de podcasting de língua portuguesa do mundo e possuiu milhares de canais e programas no ar, alimentados por colaboradores voluntários. Porém, esse número, que na internet impressiona, em nossa realidade não tem o mesmo peso. Pelo menos, não ainda, pois a pesquisa revela que $35,8 \%$ dos jovens não sabem o que é podcast e 19,5\% sabe, mas nunca fez download de um. Enquanto isso, 24,6\% raramente faz download, e 14,9\% frequentemente. Apenas 5,2\% afirma realizar o download de podcasts sempre. Talvez a não- popularidade desse tipo de mídia ocorra justamente pela grande oferta de informação.

Quando questionados sobre qual seriam os assuntos mais interessantes para se ouvir no rádio, a grande vencedora foi a música, com $71,5 \%$ da escolha masculina e $81 \%$ feminina. Para Santini (2005), a música faz parte de todos os momentos da vida das pessoas, funcionando como uma verdadeira trilha sonora. Logo, este primeiro lugar 
com larga vantagem faz sentido. Enquanto isso, os próximos colocados na lista diferem para jovens homens e jovens mulheres. Segundo os jovens do sexo masculino, os assuntos que preferem são: futebol $(52,8 \%)$, piadas $(40,3 \%)$ e festas/shows $(22,2 \%)$. Já as mulheres preferem ouvir sobre festas/shows (36\%), cinema/filmes em geral $(32,7 \%)$, piadas $(26,3 \%)$ e futebol $(22 \%)^{5}$. Outro dado relevante é que o assunto "tecnologia" é buscado por 13,9\% dos homens e 13,7\% das mulheres. Nada mais adequado, que este seja um tema de interesse, considerando-se que hoje todos vivem "em rede". Dentre os assuntos "mais sérios", o da previsão do tempo se destaca com 14,6\% da predileção masculina e 18,5\% feminina. Enquanto informações do trânsito e política ficaram mais abaixo, com 10,9\% e 11,2\% do índice geral, respectivamente. Curiosamente, embora 2010 tenha sido um ano de eleições no Brasil, esse não parece ser um assunto interessante para os jovens pesquisados. Segundo Santini (2005), os jovens nascidos a partir de 1990, diferentemente dos jovens das décadas de 60 e 70, não almejam fazer algum tipo de revolução política ou sexual. Ou seja, mudar o mundo não é com eles. Argumento reforçado por Rocha e Pereira (2009), ao afirmar que o adolescente globalizado vive em um mundo pós-moderno e fragmentado, onde o pensamento individualista se sobressai ao pensamento revolucionário das gerações anteriores.

\section{CONCLUSÕES}

Definir com clareza como o público jovem se relaciona com o rádio na atualidade não é uma tarefa fácil. Isso se deve ao imenso número de variáveis existentes nessa equação e, principalmente, pela crescente popularização das novidades tecnológicas que invadem nossas vidas como um todo.

O jovem de hoje faz parte de uma geração que cresceu com o computador e com a internet. Logo, imaginar qualquer tipo de relação sem o intermédio dessa ferramenta é algo praticamente impossível. Ignorar tais fatos é dar às costas a um futuro que já está presente. Nesse contexto, Rocha \& Pereira (2009, p. 100) afirmam:

Em casa, na rua, no trabalho, no lazer, na mochila de um adolescente, os gadgets nos lembram como o mundo está ficando cada vez menor, mas também de infinitas perspectivas e múltiplos cenários, em toda a sua ambivalência e fragmentação.

É exatamente nestes múltiplos cenários e inúmeras possibilidades que devemos trabalhar. A pesquisa demonstra que o rádio ainda tem seu espaço cativo na vida dos jovens, mas a maneira com que eles se relacionam com esse meio é que está mudando. A maioria dos jovens entrevistados ouve rádio no carro, ou no celular/mp3 player. Logo, o rádio acaba se tornando um "veículo de movimento", visto que outras mídias como a TV e a internet praticamente requerem atenção exclusiva do indivíduo, impossibilitando, por exemplo, que ele dirija (ou caminhe pela rua) e a utilize ao

\footnotetext{
${ }^{5}$ Número provavelmente impulsionado pela realização, em 2010, da Copa do Mundo na África do Sul e, em 2014, no Brasil.
} 
mesmo tempo (pelo menos, até o momento, no Brasil).

Outro dado bastante relevante da pesquisa realizada é que jovens do sexo feminino ouvem mais rádio por dispositivos móveis (celulares, mp3 player e similares) do que os jovens homens, que preferem ouvir seu próprio playlist.

Logo, imaginar que o "velho rádio" esteja com os dias contados não é algo correto. Com o passar do tempo, novas mídias surgem e as antigas precisam se adaptar à "mais atual" realidade. Segundo Jenkins (2009), essa convergência não está ligada somente à questão dos aparelhos físicos e sim da capacidade que devemos ter de renovar ideias e conceitos. Ainda segundo o autor:

A convergência exige que as empresas de mídia repensem antigas suposições sobre o que significa consumir mídias, suposições que moldam tanto decisões de programação quanto de marketing. Se os antigos consumidores eram tidos como passivos, os novos consumidores são ativos. Se os antigos consumidores eram previsíveis e ficavam onde mandavam que ficassem, os novos consumidores são migratórios, demonstrando uma declinante lealdade a redes ou a meios de comunicação (Jenkins, 2009, p. 47).

É neste ponto que entram as rádios. A tarefa de conquistar e reter seu público-alvo nunca foi tão difícil. Por isso, é preciso procurar novas soluções para antigos problemas, pensando no público como um todo, mas considerando seus diferentes aspectos.

O jovem pesquisado é um ser extremamente tecnológico. Estar por dentro de tudo o que está acontecendo é o mínimo que ele espera. E, com a verdadeira avalanche de informações que recebe diariamente, o rádio acabou se tornando apenas mais uma mídia entre tantas outras. Nessa onda, a internet tomou a frente. Com todo o apelo de suas redes sociais e suas características multimídia, o computador acabou por se tornar TV, rádio, jornal, etc. Tudo ao mesmo tempo e agora. Talvez o que ainda incomode um pouco esses jovens seja o antigo modelo ainda adotado por algumas emissoras. Neste sentido, inovar é preciso, para poder atender a um público que busca novidades sempre. Pois ele não deixou de ouvir música e nem de ouvir rádio. E, certamente, não vai deixar de fazê-lo. Apenas mudou o meio pelo qual os consome. A televisão não acabou com o rádio, e nem a internet acabou com a televisão. Todas essas mídias continuam em nossas vidas, mas de maneiras e com importâncias diferentes.

Afinal, as mídias mudam nossos relacionamentos e nossos relacionamentos mudam as mídias. É uma roda gigante que não pára de rodar. E, exatamente por isso, não se pode descer dela. É um mundo envolto em constantes transformações, onde é impossível imaginar com clareza o que vem a seguir. Mas pelo menos, todos estão convidados a conhecer. 


\section{REFERÉNCIAS}

ABEP (2010). Critério Classificação Econômica Brasil. Consultado o 04/05/2010, Disponível em: www.abep.org.br.

Buchalla, A. P. (2009). A juventude em rede, em Veja, ano 42, nº 7, p. 84-93.

Costa, A. C. G.: Juventude: uma breve aproximação conceitual do tema. Consultado o 06/04/2010, Disponível em: www.cmjbh.com.br. .

Dayrell, J. T. \& Gomes, N. L. (2010). A Juventude no Brasil. Consultado o 27/04/2010, Disponível em: $\underline{\text { www.cmjbh.com.br.. }}$

Dossiê MTV Universo Jovem 4" (2008). São Paulo: MTV.

E-LIFE. Consultado o 26/04/2010, Disponível em: www.elife.com.br.

Ferrarreto, L. A. (2000). Rádio: o veículo, a história e a técnica. Porto Alegre: Sagra.

Herschmann, M. \& Kischinhevsky, M.: A geração podcasting e os novos usos do rádio na sociedade do espetáculo e do entretenimento, em Revista FAMECOS, no 37, p. 101106.

Jenkins, H. (2009). Cultura da Convergência. São Paulo: Aleph.

Kischinhevsky, M. (2009). O rádio sem onda. Rio de Janeiro: E-papers.

Lemos, A. \& Cunha, P. (Orgs.) (2003). Olhares sobre a Cibercultura. Porto Alegre: Sulina.

Mattar, F. N. (2001). Pesquisa de marketing. São Paulo: Atlas.

McKinsey \& Company. Consultado o 27/04/2010, Disponível em: www.mckinsey.com.

Menandro, M. C. S.; Trindade, Z. A. \& Almeida, A. M. de O. (2003). Representações sociais da adolescência/juventude a partir de textos jornalísticos (1968-1974 e 19962002), Arquivos Brasileiros de Psicologia, Vol. 55, (1), 43-55.

Michaelis. Moderno dicionário da língua portuguesa. Consultado o 20/04/2010, Disponível em: http://michaelis.uol.com.br.

Rabaça, C. A. \& Barbosa, G. G. (2001). Dicionário de Comunicação. Rio de Janeiro: Elsevier.

Rocha, E. \& Pereira, C. (2009). Juventude e consumo - um estudo sobre comunicação na 
cultura contemporânea. Rio de Janeiro: Mauad X.

Santini, R. M. (2005). Admirável Chip Novo. Rio de Janeiro: E-papers.

Savage, J. (2009). A criação da juventude - como o conceito de teenage revolucionou o século $X X$. Rio de Janeiro: Rocco.

\section{Rodrigo Lúcio Cardoso:}

Pós-graduando em Gestão e Planejamento Empresarial e Bacharel em Comunicação Social, habilitação em Publicidade e Propaganda, pela Universidade Luterana do Brasil (ULBRA). Atualmente é comunicador e sound designer da rádio Pop Rock FM.

\section{Cristianne Maria Famer Rocha:}

Professora Adjunta da Universidade Federal do Rio Grande do Sul (UFRGS), no Curso de Análise de Políticas e Sistemas de Saúde - Bacharelado em Saúde Coletiva. Professora Convidada da Universidad para la Cooperación Internacional (UCI), na Costa Rica. Foi Professora Visitante (2008) e Professora Colaboradora (2009-2010) do Instituto de Higiene e Medicina Tropical da Universidade Nova de Lisboa (IHMT/UNL), em Portugal. Doutora em Educação (UFRGS), Mestre em Educação (UFRGS). Realizou estágio de Pós-Doutorado junto à Organização Pan-Americana de Saúde (OPAS/OMS), em 2005. É Especialista em Equipes Gestoras de Sistemas e Serviços de Saúde pela Universidade Federal do Rio Grande do Sul (2004). 